\title{
Greenhouse gas emissions from agricultural irrigation in China
}

\author{
Xiaoxia Zou • Yu'e Li • Kuo Li • Roger Cremades • \\ Qingzhu Gao • Yunfan Wan • Xiaobo Qin
}

Received: 31 January 2013 / Accepted: 17 July 2013 / Published online: 3 September 2013

(C) The Author(s) 2013. This article is published with open access at Springerlink.com

\begin{abstract}
Global change caused by increasing greenhouse gas (GHG) emission has become a common concern of the international community. As the largest emitter of GHGs and the second largest irrigator in the world, a clear understanding of how much GHG is emitted from irrigation in China is of great importance. But no previous studies address this question. So based on Chinese official statistical data, this study estimates GHG emissions from agricultural irrigation in order to inform strategies for reasonable use of water resources and emission reduction. The study finds that in 2010 the total carbon dioxide $\left(\mathrm{CO}_{2}\right)$ equivalent $\left(\mathrm{CO}_{2}\right.$-e $)$ emission from agricultural irrigation is 36.72 54.16 Mt. Emissions from energy activities in irrigation (including water pumping and conveyance) account for $50 \% \sim 70 \%$ of total emissions from energy activities in the agriculture sector. Ground water pumping is the biggest emission source, accounting for $60.97 \%$ of total irrigation emissions. Given the extent of global ground water over exploitation, balancing conservation and exploitation of ground water resources is very important to both emission reduction and sustainable development. The GHG emission intensity of irrigation depends largely on water use efficiency, so improvement of water use efficiency (both technical and managerial) can be an effective way to reduce emissions. Enhanced overall management of water utilization, balanced exploitation of water resources to avoid excessive ground water consumption, and active promotion of water use efficiency can contribute to reducing GHG emissions and pressure on water resources and advance sustainable agricultural production.
\end{abstract}

Keywords Agricultural irrigation - Climate change - GHG emission · Ground water pumping · Surface water pumping $\cdot$ Water conveyance $\cdot$ Equipment production

X. Zou $\cdot$ Y. Li $(\bowtie) \cdot$ K. Li $\cdot$ Q. Gao $\cdot$ Y. Wan $\cdot$ X. Qin

Institute of Environment and Sustainable Development in Agriculture (IEDA),

Chinese Academy of Agricultural Sciences (CAAS), 10081 Beijing, China

e-mail: yueli@ami.ac.cn

X. Zou

e-mail: zzouxiaoxia666@126.com

R. Cremades

Higher Polytechnic School of Gandia, Universitat Politècnica de València, C/ Paranimf, 1, 46730 Gandia, Valencia, Spain 


\section{Introduction}

Global change caused by increasing greenhouse gas (GHG) emission has become a common concern of the international community. Many natural systems are being affected by global change, which causes widespread melting of snow and ice, rising global average sea level and increasing extreme climate events including drought, heavy precipitation and tropical cyclones, all of which have disrupted human life to some extent (IPCC 2007). Global change therefore not only matters to the interests and development of each country, but to the whole world. Since 2010, China has become the largest GHG emitter in the world and its GHG emissions have drawn widespread attention both domesticically and internationally.

China is a major producer of agricultural crops. For decades, agricultural production has been the basis of economic development, and a policy priority of the Chinese government. Due to the indispensable role of water in agriculture, the development of agricultural irrigation has been deemed an effective measure to ensure food production (CCCPCSC 2010). In the past three decades, China has steadily increased its investments in irrigation projects, increasing spending from 236 million CNY (Chinese yuan) (according to the discount rate $12 \%$, the present value in 2010 is 2136.98 million CNY) in 1981 to 33.43 billion CNY in 2010. (The average exchange rate of US dollar to CNY in 2010 is 6.77 (NBSC 2011)). During this period, the irrigated area has increased from 49 million ha to 60 million ha, and the area under water-saving irrigation techniques has increased from 16 million ha in 2000 to 27 million ha in 2010 (MWR 2011) (Fig. 1). China is now the second largest irrigator in the world, and over $70 \%$ of national food production is from irrigated agriculture (Wu et al. 2006). Due to the effects of climate change (WGCNAPCC 2011) coupled with the effects of industrialization, urbanization and population growth, water resources management remains a major challenge in sustainable agricultural production and food security (Fedoroff et al. 2010). In recent decades, on average each year 12.64 million ha of farmland are afflicted with drought, of which 56.71 suffer significant crop loss (MWR 2011). Water use efficiency of agriculture in China (0.5) is still much lower than that of other good performers in the world, such as Israel and the US (the United State) (0.7-0.8) (Zhou 2010). Under such circumstances, China has launched a roadmap to raise water use efficiency to

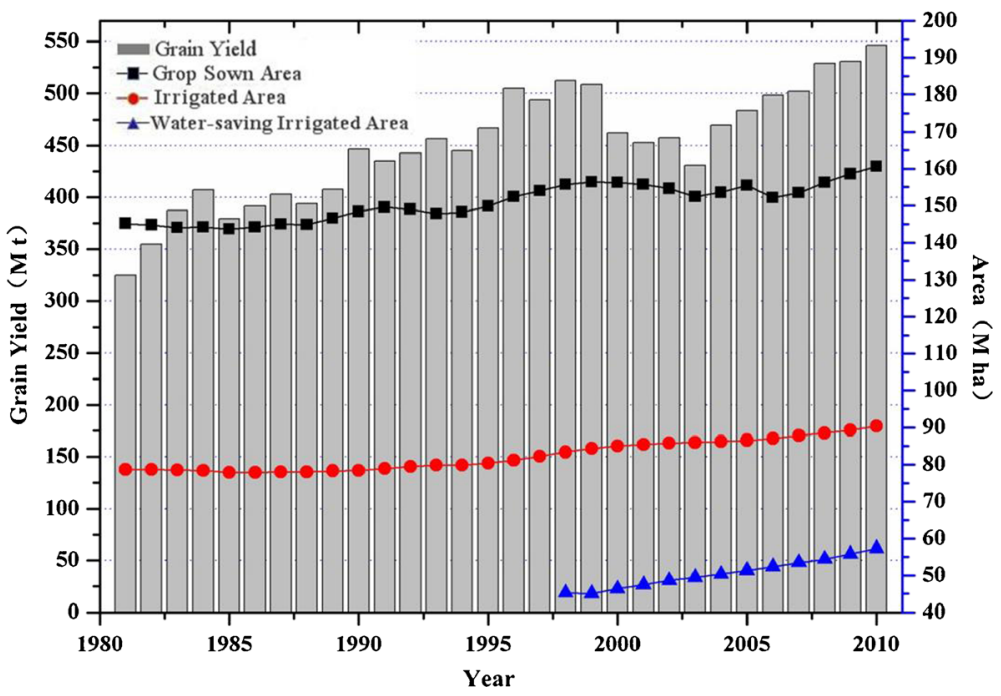

Fig. 1 The development of irrigation in China in the last 30 years (Source: MWR 2011) 
0.6 by 2030 (Hu et al. 2011; GPRC 2011). This objective can only be attained if there is largescale development of irrigated agriculture.

Expansion of irrigated area is bound to increase investment in irrigation machinery and energy consumption, which will consume large amounts of fossil energy and release huge amounts of $\mathrm{CO}_{2}$ (Pimentel and Pimentel 2003; Gleick et al. 2002). Studies have found that irrigation emits large amounts of GHGs. In the Philippines, pumping machinery for irrigation used in pumping station emits $472 \mathrm{~kg} \mathrm{CO}_{2}$ /ha and in channel ling $454 \mathrm{~kg}$ /ha quarterly (Maraseni et al. 2010). In Iran, ground water pumping consumes 2.05 billion $\mathrm{kWh}$ of electricity and 2 million $\mathrm{t}$ of fuel each year, leading to emissions that account for $3.6 \%$ of the country's total GHG emissions (Karimi et al. 2012). In the US, $23 \%$ of on-farm energy use for crop production is for on-farm pumping (Sloggett 1982), and water-related energy use accounts for about $13 \%$ of the nation's electricity consumption (GriffithsSattenspiel and Wilson 2009). So far, studies in China have only covered GHG emissions from ground water pumping (Wang et al. 2012). The emissions from surface water pumping, conveyance and equipment production have remained unresearched. Based on newly published official data,

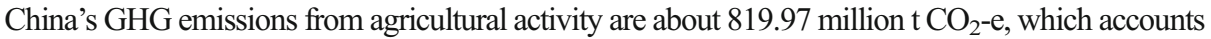
for $11.64 \%$ of total net GHG emissions, and the emissions from agricultural energy use (66.73 Mt $\mathrm{CO}_{2}-\mathrm{e}$ ) accounted for $1.24 \%$ of total emissions from energy activity in 2005 (NDRCC 2012). So as the largest GHG emitter and the second largest irrigator in the world, GHG emissions from irrigation in China may be of great important to global GHG emissions.

A clear picture of GHG emissions for different sectors is a key guide to identification of options for emission reduction. Given the importance of irrigation to agriculture and the multiple stresses on water resources, clarifying GHG emissions from each process and technique of irrigation is necessary to identify strategies for emissions reduction and reasonable development of irrigated agriculture. Based on official statistical data and market surveys, this paper estimates GHG emissions from four processes of irrigation (ground water pumping, surface water pumping, water conveyance and irrigation equipment production) and five of the most popular irrigation techniques in China (traditional irrigation, sprinkler irrigation, micro-irrigation, low pressure pipe irrigation, canal lining irrigation).

\section{Materials and methods}

This paper provides estimates for the year 2010, which was the last year of Eleventh Five-Year Plan for National Socio-economic Development ${ }^{1}$ and is the reference year for targets set out in the Twelfth Five-Year Plan. At the end of 2010, the Chinese government approved the outline of the "12th Five-Year Plan", in which green and low-carbon development was important policy priorities. For the first time, the outline plan set the reduction of $\mathrm{CO}_{2}$ emission intensity per unit of GDP by $17 \%$ as a binding target, and further specified the key tasks for GHG emission control (NDRC 2012). This initiative of the Chinese government may be a turning point in global economic development (Roach 2011; Coulter and Yang 2010), so the emission inventory in 2010 is particularly significant.

Data on pumped irrigation acreage, areas under different irrigation techniques and the colume of water consumed come from the China Water Statistical Yearbook (MWR 2011). Data on the lifting head of pumping stations in different provinces are based on the "2008 China Irrigation and Drainage Development Study" (CIDDC 2009) and the Water

\footnotetext{
${ }^{1}$ Five-Year Plan is part of China's economic and social development plan, which planning national major construction projects, productivity distribution and important proportional relation of national economy with the aim to state objectives and direction for the development of the national economy in the next 5 years.
} 
Resources Record of 30 provinces and regions in China. Parameters in the equations come from industry standards and market research. Water saving rates and carbon intensity of production of per mass of materials used for water saving irrigation came from published papers and if the number of data points was more than 5 , the $95 \%$ confidence level was used, and if the number of data points was less than this, the average was used.

The main uncertainty in the paper relates to parameters settings. There could be differences in equipment parameters between different regions, but considering the lack of statistical data, for conservative analysis, the paper adopts the principle of the minim industry limits and expert advice in selecting parameters. For details on how parameters were set, please refer to 2.2.2. In order to reduce bias, the paper is based on provincial data in all its calculations and data sources cover regions at different development levels in China, except Hong Kong SAR (Special Administrative Region), Macao SAR and Taiwan. In this study, calculations are made in a relatively idealized state without considering the water lost or returned in the transport process. Data and graphics were processed using Office 2010 and Origin 8.

\subsection{Research scenario}

The calculation of GHG emissions from irrigation processes involves four parts:

1) Surface water pumping: GHG emissions resulting from energy consumed by machinery for pumping water (used only for agricultural irrigation) from surface water sources, such as rivers, lakes and ponds to higher farmland.

2) Ground water pumping: GHG emissions resulting from energy consumed by machinery for pumping water (used only for agricultural irrigation) from underground water sources, which is mainly pumping wells.

3) Water conveyance: GHG emissions resulting from energy consumption for the conveyance of pumped water (both ground and surface water).

4) Production and construction of irrigation facilities: GHG emissions resulting from the production and construction of power machines, conveying appliances, watering devices and fittings associated with all irrigation techniques studied in this paper.

GHG emissions were calculated for irrigation techniques in six categories:

According to Chinese irrigation development plans and official statistics, there are two main categories of irrigation techniques: traditional irrigation (TI) and water-saving irrigation (WSI). The latter is further sub-divided into five sub-categories: sprinkler irrigation (SI), microirrigation (MI), low pressure pipe irrigation (LI), canal lining irrigation (CI) and other watersaving irrigation (OI, i.e., any WSI technique not in the above four categories) (MWR 2011). The calculation of GHG emissions from irrigation techniques covers these six categories, and under each category the GHG emissions for the above four processes are calculated. Basic information on the irrigation techniques in 2010 is shown in Fig. 2. Other water-saving irrigations are not specified in the statistical data, so the minimum value of all WSI techniques is used to calculate OI.

\subsection{Calculation of GHG emissions from water pumping and conveyance}

\subsubsection{Equations for calculation}

For the calculation of energy consumption during water (ground water and surface water) pumping processes, three methods (Karimi et al. 2012; Rothausen and Conway 2011; Lin 


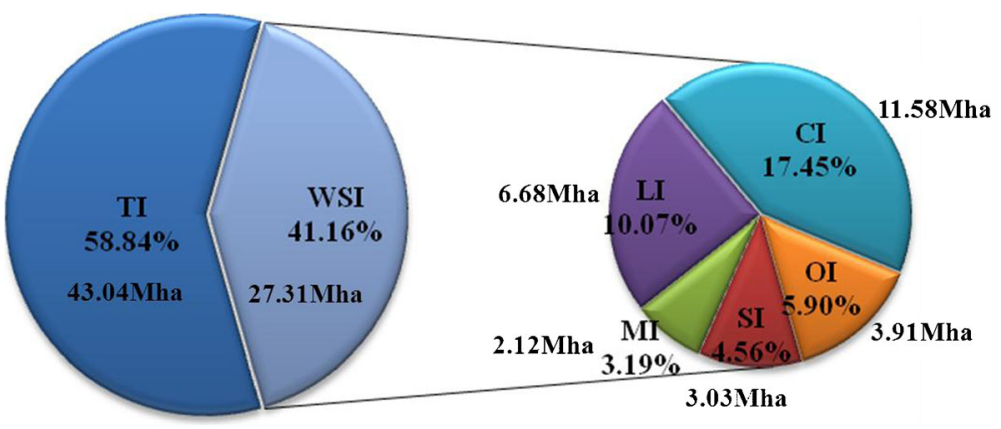

Fig. 2 Areas and proportion of different irrigation techniques in 2010 in China (Source: MWR 2011). Note: Irrigated area includes arable land, forest, orchard, grassland and other land for agricultural production

1984) were assessed. On the basis of Chinese irrigation conditions and data availability, the method of Lin (1984) was chosen for calculation:

$$
E_{\mathrm{i}}=\frac{\gamma m_{\mathrm{i}} \mathrm{A}_{\mathrm{i}} \mathrm{H}}{1000 * \eta} * E_{b}
$$

Where:

A irrigated area (ha)

$E \quad$ energy consumed in pumping irrigation ( $\mathrm{kWh}$ or $\mathrm{kg}$ )

M annual average irrigation water per unit area $\left(\mathrm{m}^{3} / \mathrm{ha}\right)$

$\mathrm{H}$ pumping head during lifting (including head loss) (m)

$\eta \quad$ efficiency of a pumping equipment during lifting (\%)

$E_{b} \quad$ unit energy consumption of lifting equipment $(\mathrm{kWh} /(\mathrm{ktm})$ or $\mathrm{kg} /(\mathrm{ktm}))$

$\gamma \quad$ unit weight of water $\left(1,000 \mathrm{~kg} / \mathrm{m}^{3}\right)$

i irrigation technique.

During the water conveyance process, pressure is needed to push water a certain distance, so according to the energy consumption measure (Lin 1984), Eq. (2) is used for calculation:

$$
E_{\mathrm{i}}^{\prime}=\frac{\gamma m_{\mathrm{i}} A_{\mathrm{i}} H_{\mathrm{i}}^{\prime}}{1000 * \eta^{\prime}} * E_{\mathrm{b}}
$$

Where:

$E^{\prime} \quad$ energy consumption for pressurizing ( $\mathrm{kWh}$ or $\left.\mathrm{kg}\right)$

$H^{\prime}$ pressure head for irrigation equipment (m)

$\eta^{\prime} \quad$ efficiency of pressurizing equipment $(\%)$

Other factors are defined as above.

\subsubsection{Setting of the parameters in the equations}

The irrigated area and the volume of water used for irrigation were obtained from China Water Statistical Yearbook. Agricultural machines in China mainly include electric motors and diesel engines. Of all drainage and irrigation machinery in 2010, diesel engines accounted for $44.6 \%$ of machines, and electric motors for $55.4 \%$ (DRSES 2012). 
1) Unit energy consumption (Eb)

In China, there is no statistical data on unit energy consumption in each province, but according to the national industrial standard Code of Practice for Technical Renovation of Pumping Stations, unit energy consumption (i.e., energy consumed to pump and lift $1,000 \mathrm{t}$ of water by $1 \mathrm{~m}$ ) of an electrical irrigation station shall not be more than $5 \mathrm{~kW} \cdot \mathrm{h} /$ $(\mathrm{kt} \cdot \mathrm{m})$, and that of a diesel engine irrigation station shall not be more than $1.35 \mathrm{~kg} /$ $(\mathrm{kt} \cdot \mathrm{m})$ (MWR 2000). These industry limits were used in the calculations.

2) According to the national industrial standard Code for Design of Irrigation and Drainage Engineering, the device efficiency of an axial flow pumping station with a net pumping head higher than $3 \mathrm{~m}$ should be higher than $70 \%$; that of an axial flow pumping station with a net pumping head lower than $3 \mathrm{~m}$ should be higher than $60 \%$; that of an electrical motor-pumped well should be higher than $45 \%$; and that of a diesel engine pumped well should be higher than $40 \%$ (GAQS and MHUD 1999). Official statistical data shows that the average pumping head of irrigated areas in each province is higher than $3 \mathrm{~m}$, and more than $90 \%$ of the area irrigated by pumping wells has been equipped with electrical motors. Therefore, in the calculation, the value of device efficiency $\eta$ of a pumping station is set as $70 \%$. Assuming that all pumping wells are electrical motor-driven, the efficiency $\eta$ of a pumping device is set as $45 \%$. As for the pressurizing efficiency $\eta^{\prime}$, no definite data are available. According to experts, efficiency is uniformly assumed to be $50 \%$.

Efficiency of pumping equipment $(\eta)$ and pressurizing equipment $\left(\eta^{\prime}\right)$

3) Setting of pressure head

When SI is applied, the pressure head of the sprinkler in operation is mostly higher than $20 \mathrm{~m}$ (GAQS and MHUD 2007), while that of LI is lower than $15 \mathrm{~m}$, and that of MI is much lower (Li and Ma 2002; Zhang and Li 2007). Therefore, in the calculations, the pressure head of SI is set at $25 \mathrm{~m}, \mathrm{LI}$ is set at $10 \mathrm{~m}$, and MI is set at $5 \mathrm{~m}$.

4) Water pumping head

Data on water pumping heads of pumping stations at provincial level have been obtained

Table 1 Lift head of surface and ground water pumping in China, Unit: $m$

\begin{tabular}{llllll}
\hline Province & Surface water & Ground water & Province & Surface water & Ground water \\
\hline Hubei & 29.37 & 28.72 & Hebei & 43.83 & 46.90 \\
Jiangxi & 18.24 & 30.99 & Henan & 49.60 & 29.01 \\
Anhui & 24.50 & 29.26 & Shandong & 30.51 & 34.33 \\
Jiangsu & 7.80 & 31.59 & Sichuan & 36.87 & 26.61 \\
Zhejiang & 4.81 & 37.11 & Ningxia & 38.9 & 29.30 \\
Guangdong & 9.30 & 27.31 & Xinjiang & 50.00 & 63.00 \\
Liaoning & 7.00 & 26.71 & Guizhou & 56.70 & 30.90 \\
Fujian & 17.57 & 35.07 & Hainan & 42.00 & 35.64 \\
Heilongjiang & 14.56 & 33.13 & Hunan & 67.40 & 28.75 \\
Jilin & 16.51 & 30.05 & Beijing & 43.83 & 41.42 \\
Gansu & 100.00 & 41.95 & Shannxi & 97.56 & 58.33 \\
Qinghai & 60.68 & 45.79 & Inner Mongolia & 50.00 & 45.24 \\
Chongqing & 39.58 & 33.67 & Tibet & 50.00 & 26.66 \\
Guangxi & 25.85 & 28.08 & Yunnan & 78.83 & 38.54 \\
Shanxi & 41.99 & 43.17 & Tianjin & 43.83 & 54.60 \\
\hline
\end{tabular}


from Water Resources Records of 30 provinces and regions in China and 2008 China Irrigation and Drainage Development Study, please see Table 1.

There are no valid statistics on ground water pumping head in China. Research reported in Wang et al. (2012) on 366 villages in China showed that there is correlation between the pumping head of ground water and the ground water level (see Eq. (3)). Based on data from monitoring stations on ground water levels in 2010 (CGEM 2011), ground water pumping heads at provincial level were estimated as in Table 1:

$$
y=0.906 x+21.75\left(R^{2}=0.62, n=366\right)
$$

Where:

y ground water pumping head $(\mathrm{m})$;

$\mathrm{x}$ ground water level (m).

5) Water saving rate

Reference data on WSR were selected based on the main crops irrigated and no obvious crop yield reduction is caused. From published papers, the water saving rate of LI, MI, CI and SI were collected and the $95 \%$ confidence interval for each technique was calculated. As noted above, there is no specific data on OI, so as a conservative estimate the minimum value principle was used. The water saving rate of each technique compared with traditional irrigation is shown in Table 2. For details of these data see Zou et al. (2012).

\subsubsection{The Calculation of GHG Emissions from the energy activities in agricultural irrigation}

Based on the equations and parameters, energy consumed by machinery for ground water pumping, surface water pumping and water conveyance under various irrigation techniques can be calculated. The $\mathrm{CO}_{2}$ equivalent $\left(\mathrm{CO}_{2}\right.$-e) emissions from diesel consumption are calculated assuming a $\mathrm{CO}_{2}$-e emission factor for diesel of $3.3 \mathrm{t} \mathrm{CO}_{2} / \mathrm{t}$ (GAQS and MHUD 2008; UNFCCC 2008), and the $\mathrm{CO}_{2}$-e emissions from electricity consumption are calculated assuming a marginal electricity emission factor of $0.9738 \mathrm{t} \mathrm{CO}_{2} / \mathrm{MWh}$ (DCC 2010). The GHG Emissions is equal to the energy consumption multiplied by its emission factor.

2.3 Calculation of GHG emissions from production and construction of irrigation facilities

The calculation of GHG emissions in this section are based on market research and experimental data.

\subsubsection{The material cost by production and construction of irrigation facilities}

1) Micro-irrigation and low pressure pipe irrigation

Published literature gives a clear indication of the number of pipes/hoses and fittings

Table 2 Water-saving rate of WSIs compared to traditional irrigation

\begin{tabular}{llcccc}
\hline Method & Average & $95 \%$ confidence interval & Method & Average & $95 \%$ confidence interval \\
\hline SI & 0.453 & {$[0.293,0.613]$} & CI & 0.245 & {$[0.138,0.352]$} \\
MI & 0.527 & {$[0.376,0.678]$} & LI & 0.294 & {$[0.208,0.379]$} \\
\hline
\end{tabular}


used for MI and LI (see Appendix Tables 7 and 8). Based on market research, the weights of the above-mentioned pipes in metric units and fittings in single unit mass are given in Appendix Tables 9 and 10.

2) Sprinkling

Two widely used products, Irrifrance Sprinkler and DYP sprinkler by Ningbo Weimengshengfei Agricultural Machinery Co. Ltd were selected for study. Detailed weights are given in Appendix Table 11. Sprinklers are commonly driven by tractors. Relevant data were collected accordingly and are shown in Appendix Table 12, with Laidong branded tractor taken as an example.

3) Canal lining

Different materials such as concrete, plastic film, masonry and clay are used as lining for a canal bed. Since there are no exact statistics on the proportion of specific materials used, this paper assumes that $50 \%$ is laid with concrete. Figure 3 presents a trapezoidal open channel with a water depth $(\mathrm{H})$ of $1 \mathrm{~m}$ as an example. According to Technical Guidelines on Seepage Control Projects (MWR 2005), the amount of concrete for $1 \mathrm{~m}$ of channel is approximately $0.32 \mathrm{~m}^{3}$, and the anti-seepage channel required for each irrigated hectare is about $180 \mathrm{~m}$ long (CIDDC 2009; MWR 2011), so the concrete used for each hectare is about $57.6 \mathrm{~m}^{3}$. According to Design Specifications on Concrete Structures (GAQS and MHUD 2010), the minimum amount of cement for a concrete structure is $300 \mathrm{~kg} / \mathrm{m}^{3}$. From the above, $8.80 \mathrm{t}$ cement is used for construction of a canal to irrigate 1 hectare.

4) Traditional irrigation

There were 21.22 million agricultural irrigation and drainage machines (motors and diesel engines) in China in 2010, which irrigated 36.40 million ha, implying 1.7 ha per machine (DRSES 2012). The irrigation machines calculated in this paper are identified as centrifugal pumps. The amount of materials used for each hectare can be estimated based on the above market research. Equipment used in each irrigation technique has a certain service time. The lifetime of MI is about 10 years, SI is about 15 years, LI is about 12 years and CI is about 30 years (Zou et al. 2012).

\subsubsection{The Calculation of GHG Emissions from production and construction of irrigation facilities}

The annual mass of materials per unit irrigated area of each technique was calculated based on the above information. For details, please see Table 3. Publications indicate that the production of $1 \mathrm{t}$ of steel emits 1.4 2.38 $\mathrm{t}$ of $\mathrm{CO}_{2}$-e (Ji et al. 2010; Zhang et al. 2010; Bai et al. 2010; Lu et al. 2010; Han et al. 2011; Ran and Weng 2006); the production of $1 \mathrm{t}$ of cement emits

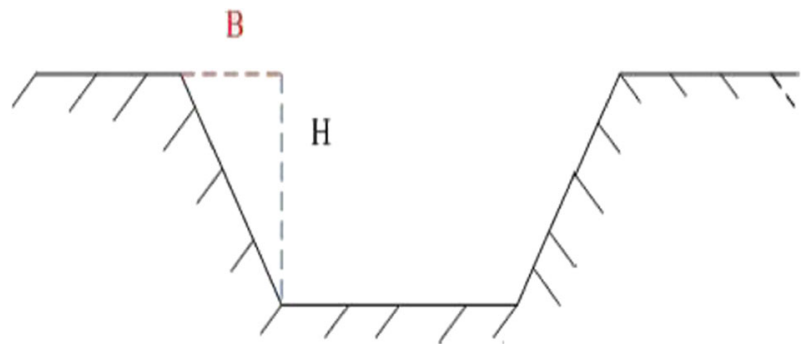

Fig. 3 Schematic diagram of cross section of canal lining irrigation 
0.61 0.99 t of $\mathrm{CO}_{2}$-e (Li et al. 2010; Wang 2006; Bai et al. 2006; Han et al. 2010; He et al. 2009); and the production of $1 \mathrm{t}$ of ethylene emits $2.51 \mathrm{t}$ of $\mathrm{CO}_{2}$-e (Bai et al. 2006). The GHG Emissions is equal to the material consumption multiplied by its emission factor.

\section{Results and analysis}

3.1 GHG emissions from ground water pumping, surface water pumping and water conveyance

Of the three irrigation processes, due to its higher pumping volume and head, ground water pumping has the largest emission, which is about three times the emission from surface water pumping (Table 4). Therefore, both a raised ground water level and reduced groundwater consumption can help reduce GHG emissions from ground water pumping.

Of each irrigation technique, due to its large area and high emissions per unit area, TI emitted the largest amount of GHGs, and more than the sum of emissions by all WSI techniques. Under the same conditions, GHGs emitted per unit area is determined by the volume of irrigated water. Compared to WSI, TI consumes more water resources, so TI ranks highest for $\mathrm{CO}_{2}$-e emissions per unit area (1.22 t), followed by CI (0.92 t), OI (0.92 t), LI (0.65 t), SI (0.55 t) and MI (0.40 t). Therefore, improvement in water use efficiency can not only help ease water shortage but also reduce GHG emissions.

\subsection{GHG emissions from production and construction of irrigation facilities}

GHGs emitted from the production and construction of irrigation facilities per unit area are shown in Table 5. Among all the techniques, CI has the highest emissions due to the large amount of cement used. Therefore, low carbon materials used for the construction of canal lining could be one way to reduce emissions.

For all the techniques, the total $\mathrm{CO}_{2}$-e emissions from production and construction of irrigation facilities stands at 5.50 10.14 Mt (Table 6), which is much lower than that from the process of water pumping and conveyance (see Section 3.1). TI has the lowest emission per unit area in this process, but due to its large irrigated area, it registers the highest total emissions.

\subsection{Total GHG emissions from agricultural irrigation}

The total GHG emissions from agricultural irrigation include surface water pumping, ground water pumping, water conveyance and production and construction of irrigation facilities (Fig. 4). In all irrigation processes, ground water pumping registers the highest emission, and for all techniques except SI and CI, the emissions from this process take up over $50 \%$ total

Table 3 Annual mass of materials per unit irrigated area, unit: $\mathrm{kg}$

\begin{tabular}{llllll}
\hline & MI & SI & LI & CI & TI \\
\hline Metal & $6.0 \sim 15.4$ & $55.1 \sim 107.7$ & $14.5 \sim 43.5$ & $14.5 \sim 43.5$ & $14.5 \sim 43.5$ \\
Plastics pipes & $75.5 \sim 95.8$ & & $23.1 \sim 30.8$ & & \\
Cement & & & & $264.1 \sim 322.7$ & \\
\hline
\end{tabular}


Table $4 \mathrm{CO}_{2}$-e emissions from water pumping and conveyance, Unit: $10^{4} \mathrm{t}$

\begin{tabular}{llrrrrrrr}
\hline & & \multicolumn{1}{l}{ MI } & \multicolumn{1}{l}{ SI } & \multicolumn{1}{l}{ LI } & CI & OI & TI & Total \\
\hline Surface water pumping & Average & 8.72 & 21.23 & 70.73 & 163.80 & 43.86 & 597.75 & 906.09 \\
& Min & 6.22 & 13.73 & 50.04 & 92.26 & 24.70 & 784.71 \\
Ground water pumping & Max & 11.22 & 28.73 & 91.18 & 235.34 & 63.02 & 1027.23 \\
& Average & 117.94 & 172.63 & 390.07 & 339.62 & 247.54 & 1597.24 & 2865.04 \\
& Min & 84.15 & 111.66 & 275.97 & 191.30 & 139.43 & 2399.74 \\
Water conveyance & Max & 151.73 & 233.60 & 502.85 & 487.94 & 355.65 & & 3329.01 \\
& Average & 11.19 & 133.16 & 107.32 & & & & 251.67 \\
& Min & 7.98 & 86.13 & 75.93 & & & & 170.04 \\
& Max & 14.40 & 180.19 & 138.35 & & & 332.94 \\
\hline
\end{tabular}

emissions. In addition, the production and construction of SI and CI facilities registers a high total emission due to the large amount of materials consumed per unit area.

An emission graph is presented in Fig. 5 that compares each of the techniques. The total GHG emissions from agricultural irrigation in China in 2010 was about 36.72 54.16 Mt $\mathrm{CO}_{2}$-e, and among all the techniques, TI contributes the largest proportion (49.74\%), followed in turn by CI $(17.34 \%)$, LI (13.58 \%), SI $(8.27 \%)$, OI $(7.08 \%)$ and MI (3.99\%). In terms of per unit hectare emissions, TI ranks first $\left(1.25 \mathrm{t} \mathrm{CO}_{2}-\mathrm{e}\right)$, followed in turn by CI and OI (9.78 $\left.\mathrm{t} \mathrm{CO}_{2}-\mathrm{e}\right)$, LI (7.56 $\left.\mathrm{t} \mathrm{CO}_{2}-\mathrm{e}\right)$, SI (7.52 $\left.\mathrm{t} \mathrm{CO}_{2}-\mathrm{e}\right)$ and $\mathrm{MI}\left(6.38 \mathrm{t} \mathrm{CO}_{2}\right.$-e), which is correlated with the mass of water consumed by these techniques for irrigating each unit area of farmland. That is to say, even if the GHG emissions from equipment production and construction are taken into account, GHG emissions from agricultural irrigation is still correlated to water use efficiency. So the improvement of water use efficiency is the most effective way to reduce emissions in agricultural irrigation.

\section{Discussion}

\subsection{GHG emissions from agriculture irrigation in China}

To date, available studies in China on GHG emissions from agricultural irrigation have focused on the emissions from ground water pumping (Wang et al. 2012). No previous study has considered emissions from the processes of surface water pumping, water conveyance and the production of irrigation facilities, which is necessary to gain a comprehensive picture of irrigation emissions. Having taken into account GHG emissions from these above mentioned three processes, this study has estimated that emissions from surface water pumping accounts for $19.28 \%$ of total emissions, that from water conveyance is $5.36 \%$ and that from the production of

Table $5 \mathrm{CO}_{2}$-e emission from production and construction of irrigation facilities per unit area, unit: $\mathrm{kg}$

\begin{tabular}{|c|c|c|c|c|c|c|}
\hline & MI & SI & LI & $\mathrm{CI}$ & OI & TI \\
\hline Average & 234.86 & 204.22 & 105.05 & 269.06 & 105.05 & 36.45 \\
\hline Min & 200.67 & 128.96 & 84.81 & 236.23 & 84.81 & 26.88 \\
\hline Max & 269.05 & 280.32 & 158.03 & 336.52 & 158.03 & 80.65 \\
\hline
\end{tabular}


Table 6 Total $\mathrm{CO}_{2}$-e emitted from production and construction of irrigation facilities, unit: $10^{4} \mathrm{t}$

\begin{tabular}{|c|c|c|c|c|c|c|c|}
\hline & MI & SI & LI & $\mathrm{CI}$ & OI & TI & Total \\
\hline Average & 49.69 & 61.78 & 70.17 & 311.58 & 41.10 & 142.29 & 676.62 \\
\hline Min & 42.45 & 39.02 & 56.66 & 273.56 & 33.18 & 104.95 & 549.82 \\
\hline Max & 56.92 & 84.81 & 105.57 & 389.70 & 61.83 & 314.84 & 1013.67 \\
\hline
\end{tabular}

irrigation facilities is $14.40 \%$, and the sum of these three processes accounts for $39.03 \%$ of the total emissions in agricultural irrigation. Nevertheless emissions from ground water pumping are still the main source, accounting for $60.97 \%$ of total emissions. Although different methods were used, the emissions estimated in our study (24.00 33.29 $\mathrm{Mt} \mathrm{CO}_{2}$-e in 2010) are close to the estimate of $33.1 \mathrm{Mt} \mathrm{CO}_{2}$-e in 2006 by Wang et al. (2012). By comparison, in India deep wells powered by electricity are the largest single source of $\mathrm{CO}_{2}$ emissions, accounting for $65 \%$ of the total emissions in 2000 (Nelson et al. 2009). Ground water irrigation techniques should therefore be a focus of attention.

In 2010 the total GHG emissions in agricultural irrigation in China were $39.04 \sim 57.03 \mathrm{Mt}$ $\mathrm{CO}_{2}$-e, of which emissions from energy activities (water pumping and conveyance) were 33.54 46.89 Mt, which is about $50 \% \sim 70 \%$ of the emissions from energy activities in agriculture in 2005 (NDRC 2012). GHG emissions in agricultural irrigation are therefore an important source of agricultural emissions.

\subsection{The use of ground water for agricultural irrigation}

The main reasons for the large proportion of total agricultural irrigation GHG emissions due to ground water pumping of are the huge pumping volume and the high pumping head. Due to excessive exploitation of ground water from the 1950s to the beginning of this century, parts of China have suffered a severe fall in ground water levels (Kendy et al. 2004; Tamanyu et al. 2009; Moiwo et al. 2009). Based on statistics from 663 Chinese monitoring stations in 2005 and 2010 , this paper finds that most parts of China report a continued declining ground water level and some parts record a drop by more than $10 \mathrm{~m}$ over this period (Fig. 6). A continued massive use of ground water for irrigation will further reduce the ground water level and increase GHG emissions from irrigation. For example, if the ground water level drops by $1 \mathrm{~m}$, under traditional

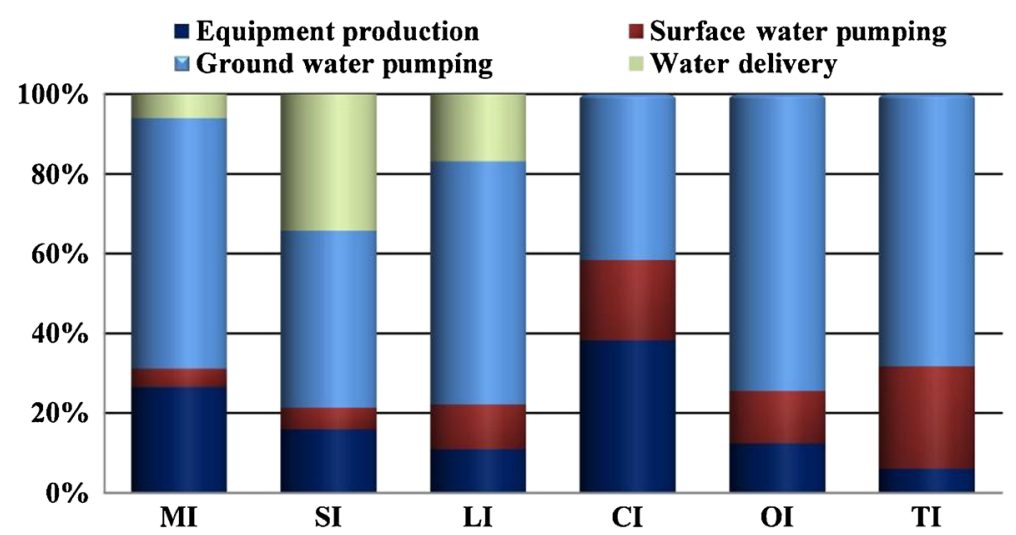

Fig. 4 The $\mathrm{CO}_{2}$-e emission proportions of different irrigation process in 2010 in China 


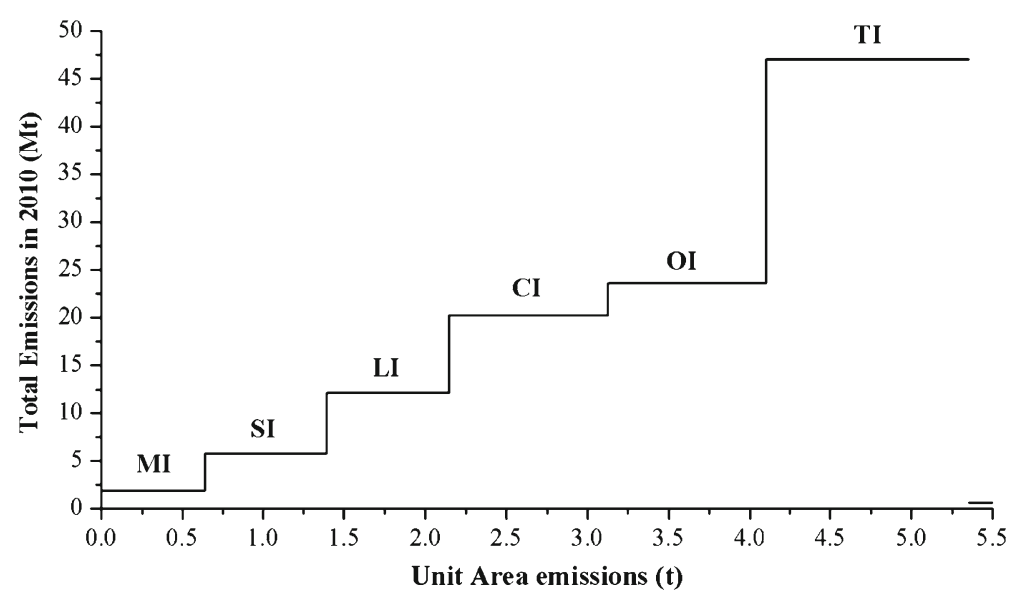

Fig. 5 Emission curve for different IrrigationTechniques. Note: In this figure, one horizontal line represents one method. The graduation of the horizontal axis that each horizontal line corresponds to represents the per unit area emission of each indicated method. The graduation of the vertical axis that each vertical line corresponds to represents the total annual emissions of each indicated method

irrigation methods in China, the $\mathrm{CO}_{2}$-e emissions from water pumping for irrigating will increase by $0.06 \mathrm{t} / \mathrm{ha}$, and for the national will increase 1.98 million tons of $\mathrm{CO}_{2}-\mathrm{e}$ emissions per year. By comparison, in US if ground water levels drop $1 \mathrm{ft}, 68,000$ metric tons of $\mathrm{CO}_{2}$-e emissions would be caused per year (Griffiths-Sattenspiel and Wilson 2009). Furthermore, excessive consumption of ground water would trigger a chain of ecological and environmental problems, such as increased salinity and pollution of ground water (Peng et al. 2003; Ding and Zhang 2002). So ground water resources must be used responsibly. In areas where ground water is quickly replenished and the water table is at a reasonable height, larger amounts of ground water can be extracted. In areas where the ground water table tends to be slow to replenish, ground water resources should not be disturbed (WHYMAP 2008).

The Worldwide Hydrogeological Mapping and Assessment Programme (WHYMAP) researched ground water from a global perspective and provided a global ground water resource map (Fig. 7). From this map it can be found that large parts of the world are overusing their ground water resources. Although we do not know the condition of ground water used in agricultural irrigation in these regions, from current ground water resources conditions and lessons from China, it is clear that there must be a conservational utilization of ground water, otherwise extraction of ground water at greater rates than ground water accumulation will cause large GHG emissions and other ecological and environmental problems (MIT 2011). Therefore, a balanced exploitation of water resources and a coordinated use of surface and ground water are very important to a successful emission reduction and sustainable development.

\subsection{The importance of improving water use efficiency}

This study finds that per unit area GHG emission intensity is correlated with water use efficiency. The higher the water use efficiency, the lower the GHG emission intensity. This result has also been found in other international studies. In India, $\mathrm{CO}_{2}$-e emissions from ground water pumping in 2000 stood at $58.7 \mathrm{Mt}$ and per hectare at $1.75 \mathrm{t}$ (Nelson et al. 2009); in the US, $\mathrm{CO}_{2}$-e 


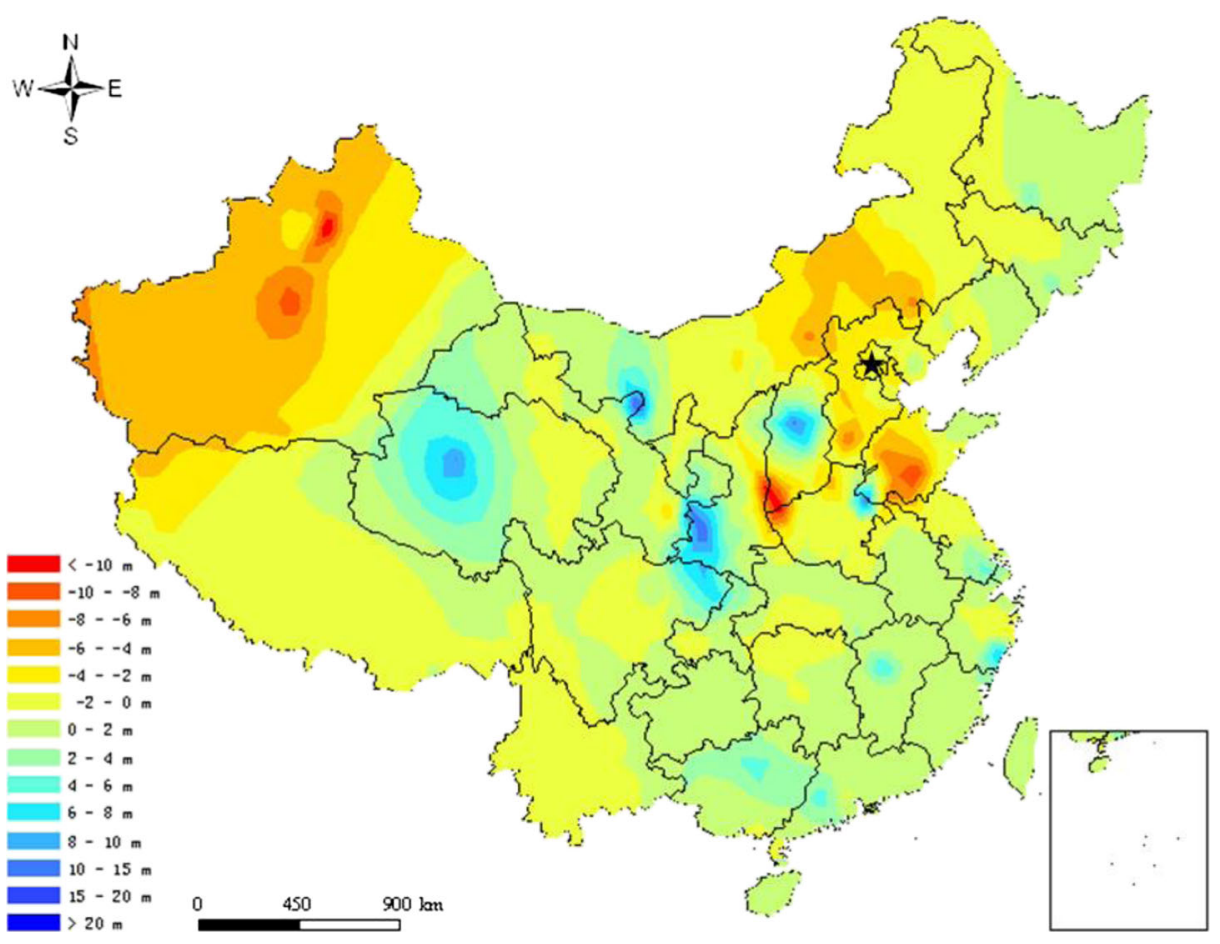

Fig. 6 Changes in ground water level in China between 2005 and 2010

emissions from irrigation in 2005 stood at $15.8 \mathrm{Mt}$ (Griffiths-Sattenspiel and Wilson 2009), which assuming an irrigated area of 58.27 million ha (USGS 2013) implies $0.27 \mathrm{t} \mathrm{CO}_{2}$-e per hectare. In China, this research finds that $0.73 \mathrm{t} \mathrm{CO}_{2}$-e would be emitted per hectare. The difference in emission intensity may arise from different calculation methods and parameters, but it depends largely on water use efficiency, which in the US is around $80 \%$ while in China and India is just $50 \%$ and $40 \%$ respectively (Tian and $\mathrm{Hu} 2006$ ). Improvement of water use efficiency is a key way to reduce emissions from irrigation, because higher water use efficiency implies less mass of water will be pumped and delivered, so less energy will be consumed and fewer GHGs will be emitted.

Although about $70 \%$ of the world's supply of freshwater is used for irrigation (IWMI 2007), in most parts of the world, water utilization is unsatisfactory. With rising demand for water resources, low irrigation water use efficiency will further cause waste of both energy and water resources, restrict water use by agriculture (Fedoroff et al. 2010; Kendy et al. 2004) and cause a series of ecological and environmental issues, such as falling ground water levels (Tamanyu et al. 2009; Moiwo et al. 2009) and land salinization (Funakawa et al. 2000; Kitamura et al. 2006). Fortunately, techniques with higher water use efficiency, such as micro-irrigation and sprinkle irrigation, can not only reduce water consumption and GHG emissions, but also alleviate the consequential soil salinization while maintaining high grain yields (Romero et al. 2006; Rajak et al. 2006; Yohannes and Tadesse 1998). However, improving irrigation efficiencies is not only achieved by improving technology, but also by regulating its usage, i.e., performing irrigation when the crops actually need the water (Stockle 2002). 


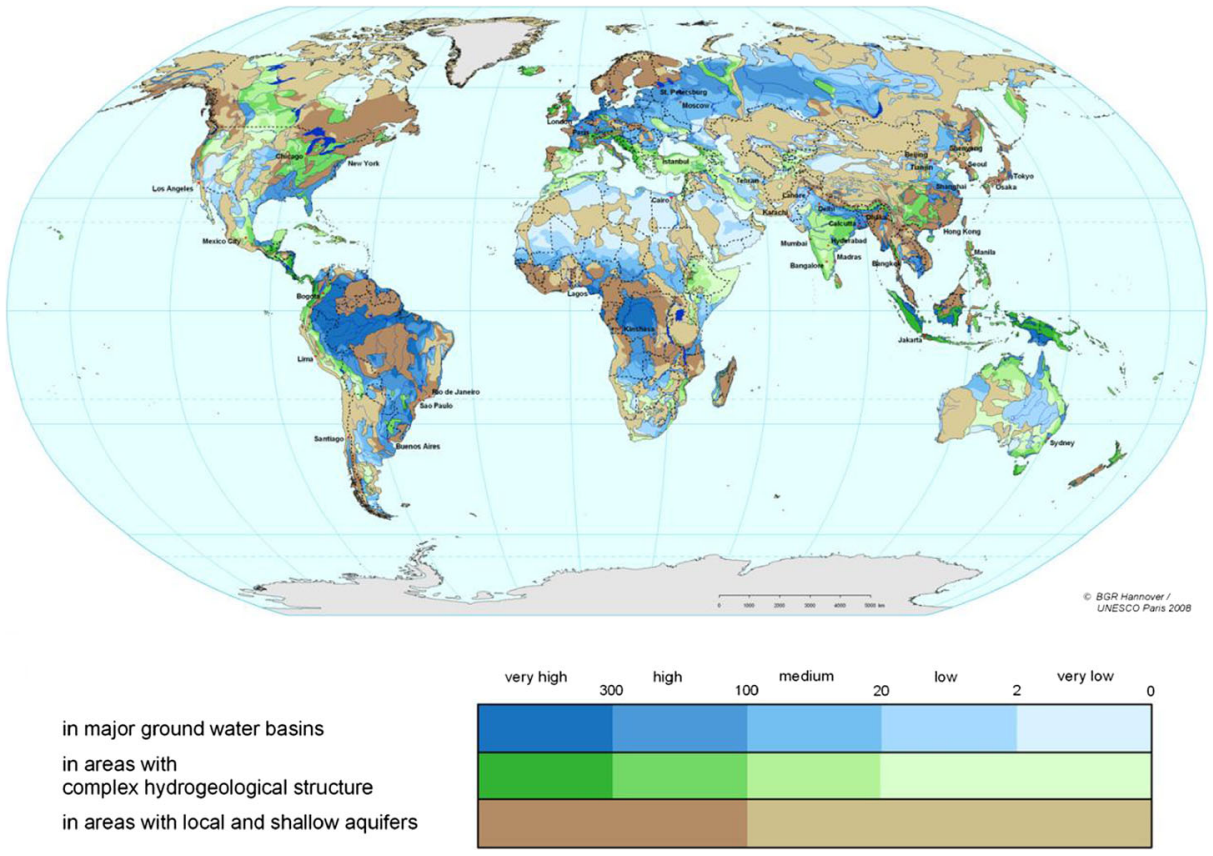

Fig. 7 Ground water resources of the world (Source: WHYMAP 2008). Note: The darker the color shade, the faster the reserve is recharged. Source: WHYMAP, 2008, http://www.whymap.org/whymap/EN/Downloads/ Global_maps/globalmaps_node_en.html

\subsection{The development of agricultural irrigation}

More than half of the freshwater in the world is used for agriculture, but agricultural production still faces the problem of water scarcity (Fedoroff et al. 2010). The International Water Management Institute (IWMI 2007) has divided the world into 4 classes of water scarcity (Fig. 8). The western part of South America, the middle part of Asia (including big areas of China, India, Pakistan, Saudi Arabia) and the Southeast of Australia are suffering physical water scarcity. Physical water scarcity not only happens in arid regions, but also in regions where water is apparently abundant, due to overdevelopment of hydraulic infrastructure, most often for irrigation (IWMI 2007). Based on our study, WSIs can improve the water use efficiency and consume less water for irrigation compared to traditional irrigation. So in regions with physical water scarcity, WSI is recommendable. However, taking the example of China, there are still some factors restricting the development of WSIs. Compared to traditional irrigation, the development of WSIs needs more funding (Li et al. 2003; Wang 2010; Yao et al. 2005); there is a higher workload associated with the control and maintenance of equipment operation (Wang and Gao 2001; Li and Fu 1998; Wang and Wu 2006); and equipment installation has higher requirements of environmental and hydrogeological conditions (GAQS and MHUD 1999; GAQS and MHUD 2007). To address these issues, the government should increase subsidies and support to WSIs to lighten the burden on farmers and foster professional and technical workers to guide farmers to effectively use WSI techniques. 


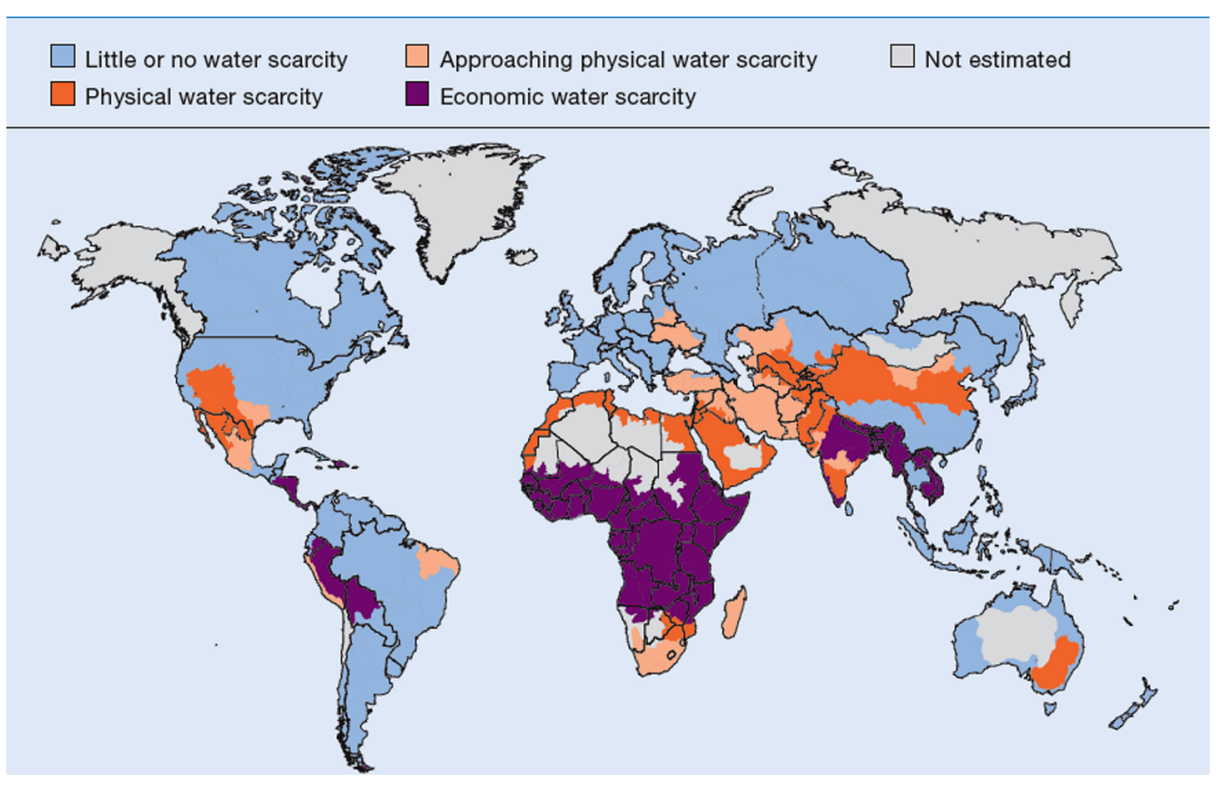

Fig. 8 Assessment of water resource in the world (Source: IWMI 2007). Note: 1) Economic scarcity is caused by a lack of investment in water or a lack of human capacity to satisfy the demand for water; 2) Physical scarcity occurs when there is not enough water to meet all demands, including environmental flows

There are large areas, such as central Africa, western North America, northern India, Bengal and Myanmar still facing economic scarcity. These regions often have scant infrastructure and residents have trouble accessing enough water for agriculture or drinking (IWMI 2007). In these regions, water scarcity may be a constraint on economic development and may be a driver of poverty and starvation. So the further water development must be carried out in these regions.

\section{Conclusions}

1) In 2010, the total $\mathrm{CO}_{2}$-e emission from agricultural irrigation is estimated at $36.72 \sim 54.16$ Mt in China, of which emissions from surface water pumping is between 7.85 10.27 Mt, ground water pumping between 24.00 33.29 Mt, water conveyance between 1.70 3.33 $\mathrm{Mt}$, and equipment production and construction between 3.17 7.27 Mt. Emissions from energy activities in irrigation (water pumping and conveyance) are equivalent to around $50 \% \sim 70 \%$ of emissions from national energy activities in agriculture in 2005.

2) Among different irrigation processes, emissions from ground water pumping are the main source, accounting for $60.97 \%$ of total emissions. Large parts of the world are currently overusing ground water resources, and a great amount of GHG emissions and ecological and environmental problems have been caused. Therefore, a balanced exploitation of water resources and coordinated use of surface and ground water resources are important for emission reductions and sustainable development.

3) Comparison of GHG emissions from different techniques on per unit irrigated area basis finds that the improvement of water use efficiency would be an effective way to reduce 
emissions from agricultural irrigation. Improving irrigation efficiency can not only be achieved by improving technology application, but also by regulating water use.

In summary, irrigation emission is a significant source of GHG emissions. Enhanced management of water resources, a balanced exploitation of water resources to avoid excessive ground water consumption, and active promotion of WSIs to improve water use efficiency can contribute to reducing GHG emissions, alleviating water shortages and advancing sustainable agricultural production.

Acknowledgments The research for this paper was sponsored by the CAS Strategic Priority Research Program (XDA05050602-02) and the Non-profit Research Foundation for Agriculture (201103039). We are very grateful to Andreas Wilkes for the assistance in revising the paper.

Open Access This article is distributed under the terms of the Creative Commons Attribution License which permits any use, distribution, and reproduction in any medium, provided the original author(s) and the source are credited.

\section{Appendix}

Table 7 Amount of materials used in micro-irrigation on per hectare (Page 6)

\begin{tabular}{|c|c|c|}
\hline Case & Materials & Source \\
\hline Drip Irrigation & $\begin{array}{l}\text { Main pipe: } 8 \mathrm{~m} \text { (PVC, DN } 110 \mathrm{~mm}), 11.50 \mathrm{~m} \\
\text { (PVC, DN } 90 \mathrm{~mm}), 13.2 \mathrm{~m}(\mathrm{PVC}, \mathrm{DN} 75 \mathrm{~mm}) \\
\text { Branch main pipe: } 17 \mathrm{~m}(\mathrm{PVC}, \mathrm{DN} 50 \mathrm{~mm}), 18 \mathrm{~m}(\mathrm{PVC}, \mathrm{DN} 40 \mathrm{~mm}) \text {, } \\
\quad 12.6 \mathrm{~m} \text { (PVC, DN } 63 \mathrm{~mm}), 9.6 \mathrm{~m}(\mathrm{PVC}, \mathrm{DN} 75 \mathrm{~mm}) ; \\
\text { Branch pipe: } 63.4 \mathrm{~m}(\mathrm{PVC}, \mathrm{DN} 63 \mathrm{~mm}) ; \\
\text { Capillary: } 3,379 \mathrm{~m} \text { (PVC, DN } 16 \mathrm{~mm}) \text {; } \\
\text { ball valve: } 12 \text {, connector: } 528 \text {, centrifugal pump: } 1 \text {, filter: } 1 .\end{array}$ & Bai et al. (2006) \\
\hline Drip Irrigation & $\begin{array}{l}\text { Main pipe: } 100 \mathrm{~m} \text { (PVC, DN } 125 \mathrm{~mm}) \\
\text { Branch main pipe: } 200 \mathrm{~m} \text { (PE, DN } 75 \mathrm{~mm}) \\
\text { Branch pipe: } 100 \mathrm{~m} \text { (PPR, DN } 40 \mathrm{~mm}) \\
\text { Capillary: } 12,500 \mathrm{~m} \text { (PPR, DN } 16 \mathrm{~mm}) \\
\text { ball valve: } 20 \text {, connector: } 250 \text {, centrifugal pump: } 1 \text {, filter: } 1 .\end{array}$ & Bai et al. (2010) \\
\hline Micro Spray & $\begin{array}{l}\text { PE: } 1,260 \mathrm{~m} \text { (DN } 32 \mathrm{~mm}), 195 \mathrm{~m} \text { (DN } 75 \mathrm{~mm}), 225 \mathrm{~m}(\mathrm{DN} 90 \mathrm{~mm}) \text {; } \\
\text { mini sprinkler: } 150 \text {, connector: } 50 \text {, plug } 45 \text {, ball valve: } 30 \text {; } \\
\text { pipe fitting } 15 \text { sets (each set include: ball valve: } 2 \text {, plug: } 2 \text {, tee: } \\
\text { 1, bend: } 1 \text {, throughway valve: } 2 \text {, quick connector: } 42 \text {, } \\
\text { capillary connector: } 42 \text { ); centrifugal pump: } 1 \text {, filter: } 1 \text {. }\end{array}$ & CCCPCSC (2010) \\
\hline Micro Spray & $\begin{array}{l}\text { PE: } 230 \mathrm{~m} \text { (DN } 63 \mathrm{~mm}), 120 \mathrm{~m} \text { (DN } 50 \mathrm{~mm}), 100 \mathrm{~m} \text { (DN } 32 \mathrm{~mm}) \text {, } \\
40 \mathrm{~m} \text { (DN } 25 \mathrm{~mm}), 3,375 \mathrm{~m} \text { (DN } 20 \mathrm{~mm}) \\
\text { mini sprayer: } 1125 \text {, ball valve: } 11 \text {, } \\
\text { pipe fitting } 3 \text { sets (each set include: ball valve: } 2 \text {, plug: } 2 \text {, tee: } 1 \text {, } \\
\text { bend: } 1 \text {, throughway valve: } 2 \text {,quick connector: } 42 \text {, capillary } \\
\text { connector: } 42 \text { ); centrifugal pump: } 1 \text {, filter: } 1\end{array}$ & CGEM (2011) \\
\hline
\end{tabular}

[1]. Zhao Y, LI G, Zhao H et al. (2004) Comparison of Pipeline Net Layout Mode between Manual Control and Automatic Control Drip Irrigation System. Water Saving Irrigation (6): 15-17, 20

[2]. Yang Z, Deng S, Zhang W et al. (2012) the Design of Drip Irrigation System. Journal of Agricultural Mechanization Research 34(4): 96-98,102

[3]. Guangdong Dahua Water-saving Technology Co., LTD http://www.nongji360.com/company/shop2/product $2358 \_14855$. shtml

[4]. Guangdong Agri-machinery Research institute. http://www.nongji360.com/company/shop2/product_2045 13193.shtml 
Table 8 Pipe type and per hectare length of low pressure pipe irrigation (Page 6)

\begin{tabular}{llll}
\hline Pipe type & Length (m/ha) & Nominal diameter (mm) & Source \\
\hline PVC & 90 & DN110 & Bai et al. (2006) \\
PVC & 115.5 & DN110 & Bai et al. (2010) and CCCPCSC (2010) \\
PVC & 17.5 & DN 160 & CGEM (2011) \\
& 50 & DN 110 & \\
PVC & 105 & DN110 & CCCPCSC (2010) and CIDDC (2009) \\
PVC & 105 & DN110 & CCCPCSC (2010) and Coulter and Yang (2010) \\
PVC & 8 & DN 180 & DCC (2010) \\
& 95 & DN 110 & \\
\hline
\end{tabular}

[1]. Xu J, Shi Z, Qiu L et al. (2003) Study on Low-pressured Pipe Optimized Design and the Technology of Its Reconstruction. JournaI of North China Institute of Water Conservancy and Hydroelectric Power 24(3): 1-3, 8.

[2]. Wang Y, Liu N, Ma Y et al. (2006) Study on the Application of the Low Pressure Pipe Irrigation Technique in the Water-Saving Agriculture of Henan Province. Henan Science 24(6): 933-936.

[3]. Wang S, and Gao C (2004) Application on the Irrigation Technology of Piping Water in Mound Region. Drainage and Irrigation Machinery 22(5): 32-34.

[4]. Agriculture Resources Development of Dujiang City. http://nkj.yangzhou.gov.cn/ztdy/200901/ 183YDMMZWUJ5EA9XS7BCENI9SGQ5DNQW.shtml

[5]. Tian Z (1993) Discussion on the Design and Construction of Pressure Pipeline Irrigation. China Rural Water and Hydropower) (12):33-35.

[6]. Guo L (2010) Design and Construction of Pressure Pipeline Irrigation Project in Well Irrigation Area. Shanxi Water Resources 26(6): 26-27.

[7]. Wang J (2004) Design and Construction of Pressure Pipeline Irrigation Project in High Lift Irrigation District. Water Saving Irrigation (5): 70-71.

Table 9 Per meter weight of PVC and PE pipe unit: $\mathrm{kg} / \mathrm{m}$ (Page 6)

\begin{tabular}{llllllllll}
\hline Pipe & DN & Min & Max & Average & Pipe & DN & Min & Max & Average \\
\hline PE & $16 \mathrm{~mm}$ & 0.13 & 0.13 & 0.13 & PVC & $40 \mathrm{~mm}$ & 0.38 & 0.78 & 0.58 \\
& $20 \mathrm{~mm}$ & 0.14 & 0.14 & 0.14 & & $50 \mathrm{~mm}$ & 0.48 & 1.22 & 0.85 \\
& $25 \mathrm{~mm}$ & 0.17 & 0.17 & 0.17 & & $63 \mathrm{~mm}$ & 0.62 & 1.95 & 1.28 \\
& $32 \mathrm{~mm}$ & 0.24 & 0.28 & 0.26 & & $75 \mathrm{~mm}$ & 0.85 & 2.74 & 1.80 \\
& $40 \mathrm{~mm}$ & 0.36 & 0.44 & 0.40 & & $90 \mathrm{~mm}$ & 1.22 & 3.96 & 2.59 \\
& $50 \mathrm{~mm}$ & 0.56 & 0.68 & 0.62 & & $110 \mathrm{~mm}$ & 1.45 & 4.90 & 3.18 \\
& $63 \mathrm{~mm}$ & 0.90 & 1.08 & 0.99 & & $125 \mathrm{~mm}$ & 1.90 & 6.37 & 4.12 \\
$75 \mathrm{~mm}$ & 1.03 & 1.51 & 1.27 & & $160 \mathrm{~mm}$ & 3.08 & 10.41 & 6.75 \\
$90 \mathrm{~mm}$ & 1.20 & 2.20 & 1.70 & & $180 \mathrm{~mm}$ & 3.82 & 13.17 & 8.50 \\
\hline
\end{tabular}

[1] http://www.doc88.com/p-039716403091.html

[2] Beijing Gold Five-star Trade Market 
Table 10 Weight of accessories for micro-irrigation unit: $\mathrm{kg}$ (Page 6)

[1] http://www.nongji360.com/

[2] Beijing Gold Five-star Trade Market

\begin{tabular}{lccr}
\hline & Average & Min & \multicolumn{1}{c}{ Max } \\
\hline Centrifugal pump & 40.38 & 23.00 & 111.00 \\
Filter & 6.08 & 1.00 & 11.00 \\
Sprayer & 0.33 & 0.10 & 0.50 \\
Ball valve & 0.75 & 0.20 & 2.30 \\
Tee & 0.13 & 0.03 & 0.37 \\
Throughway valve & 0.14 & 0.10 & 0.18 \\
Other accessories & 0.009 & 0.002 & 0.10 \\
\hline
\end{tabular}

Table 11 Weight of sprinkler irrigation equipment (Page 6)

\begin{tabular}{|c|c|c|}
\hline Brand and model & Single control area (ha) & Weight $(\mathrm{kg} / \mathrm{ha})$ \\
\hline Irrifrance $1025-1030-1035$ Single axle & 4 & 1300 \\
\hline Irrifrance Optima 1045-1055 boggie & 4.85 & 1329.90 \\
\hline Irrifrance 2060 Serie - 2075 VPS & 5.5 & 1309.09 \\
\hline Irrifrance 2060 Serie - 2075 fixed chassis & 5.5 & 1527.27 \\
\hline Irrifrance $1025-1030-1035$ Single axle & 3.85 & 1084.42 \\
\hline Irrifrance Micro 44-50 & 1.5 & 136.67 \\
\hline Irrifrance Super Mini & 2.05 & 341.46 \\
\hline Irrifrance Optima 1005-1010 & 2.15 & 930.23 \\
\hline Irrifrance Optima 1015-1020 & 3.05 & 803.28 \\
\hline Weimengshengfei DYP-70 & 1.6 & 1375 \\
\hline Weimengshengfei DYP-76 & 1.8 & 1305.56 \\
\hline Weimengshengfei DYP-82 & 2.1 & 1190.48 \\
\hline Weimengshengfei DYP-118 & 4.4 & 1000.00 \\
\hline Weimengshengfei DYP-126 & 5 & 910.00 \\
\hline Weimengshengfei DYP-132 & 5.5 & 854.54 \\
\hline Weimengshengfei DYP-138 & 6 & 808.33 \\
\hline Weimengshengfei DYP-142 & 6.3 & 793.65 \\
\hline Weimengshengfei DYP-170 & 9 & 733.33 \\
\hline Weimengshengfei DYP-176 & 9.7 & 695.88 \\
\hline Average & & 969.95 \\
\hline
\end{tabular}

Irrifrance. http://www.irrifrance.cn/index.html; Ningbo Weimengshengfei agricultural machinery Co., LTD. http://www.wmshengfei.com/cn-index.php

Table 12 Weight and rated power of Laidong Tractor (Page 6)

http://www.nongji360.com/

\begin{tabular}{lccc}
\hline $\begin{array}{l}\text { Structure } \\
\text { weight }(\mathrm{kg})\end{array}$ & $\begin{array}{l}\text { Rated } \\
\text { power }(\mathrm{kW})\end{array}$ & $\begin{array}{l}\text { Structure } \\
\text { weight }(\mathrm{kg})\end{array}$ & $\begin{array}{l}\text { Rated power } \\
(\mathrm{kW})\end{array}$ \\
\hline 1100 & 25.8 & 900 & 14.7 \\
1035 & 11.76 & 1465 & 25.7 \\
1200 & 22.1 & 1840 & 22 \\
960 & 13.24 & 1300 & 19.3 \\
1300 & 18.4 & 1520 & 29.4 \\
\hline
\end{tabular}




\section{References}

Bai B, Li X, Liu Y et al (2006) Preliminary study on $\mathrm{CO}_{2}$ industrial point sources and their distribution in China. Chin J Rock Mech Eng 25(z1):2918-2923 (in Chinese)

Bai $\mathrm{H}$, Liu P, Li H et al (2010) $\mathrm{CO}_{2}$ emission model and reduction strategy of the steelmaking industry. J Univ Sci Technol Beijing 32(12):1623-1624 (in Chinese)

CCCPCSC (Central Committee of the Communist Party of China and State Council) (2010) The no. 1 central government document-a decision to accelerate the reform and development of water conservancy. People's Publishing House, Beijing, in Chinese

CGEM (China GEO-Environmental Monitoring Institute) (2011) China groundwater level yearbook of GEOenvironmental monitoring 2010. China Land Press, Beijing (in Chinese)

CIDDC (China Irrigation and Drainage Development Center) and MWRC (Ministry of Water Resources Center for Rural Drinking Water Safety) (2009) Title of subordinate document. In: China irrigation and drainage development study of 2008. Available via DIALOG. http://www.jsgg.com.cn/Index/Display.asp?NewsID= 12496. Cited 15 May 2013

Coulter J, Yang L (2010) Global significance of china's five-year plans. World Environ 6:14-15

DCC (Department of Climate Change, National Development \& Reform Commission of China) (2010) National development \& reform commission Database. http://cdm.ccchina.gov.cn/WebSite/CDM/UpFile/File2552.pdf. Cited 15 May 2013

Ding H, Zhang J (2002) The problem of environment caused by groundwater level continuous decline in the inland basins of arid area, Northwest China - an example in Middle Reaches of Heihe River Basin. Hydrogeol Eng Geol 29(3):71-75 (in Chinese)

DRSES (Department of Rural Social and Economic Survey, National Bureau of Statistical of China) (2012) China rural statistical yearbook 2011. China Statistics Press, Beijing (in Chinese)

Fedoroff NV, Battisti DS, Beachy RN et al (2010) Radically rethinking agriculture for the 21 st century. Science (New York, NY) 327(5967):833-834

Funakawa S, Suzuki R, Karbozova E et al (2000) Salt-affected soils under rice-based irrigation agriculture in Southern Kazakhstan. Geoderma 97(1):61-85

GAQS (General Administration of Quality Supervision, Inspection and Quarantine of PRC), MHUD (Ministry of Housing and Urban-rural Development of PRC) (1999) Code of Practice for Technical Renovation of Pumping Stations. China Standards Press, Beijing (in Chinese)

GAQS (General Administration of Quality Supervision, Inspection and Quarantine of PRC), MHUD (Ministry of Housing and Urban-rural Development of PRC) (2007) Technical code for sprinkler engineering. China Standards Press, Beijing (in Chinese)

GAQS (General Administration of Quality Supervision, Inspection and Quarantine of PRC), MHUD (Ministry of Housing and Urban-rural Development of PRC) (2010) GB 50010-2010 code for design of concrete structures. Available via DIALOG. http://www.csres.com/detail/212269.html. Cited 15 May 2013 (in Chinese)

GAQS (General Administration of Quality Supervision, Inspection and Quarantine of PRC), MHUD (Ministry of Housing and Urban-rural Development of PRC) (2008) GB/T2589-2008 General principles for calculation of the comprehensive energy consumption. Available via DIALOG. http://baike.baidu.com/ view/3671869.htm. Cited 15 May 2013

Gleick P, Wolff G, Chalecki E et al. (2002) The new economy of water: the risks and benefits of globalization and privatization of freshwater. Available via DIALOG. http://www.pacinst.org/reports/new_economy_ of_water/new_economy_of_water_ES.pdf. Cited 15 May 2013

GPRC (the Government of the People's Republic of China) (2011) The twelfth five-year plan for national economic and social development of the PRC. People's Publishing House, Beijing (in Chinese)

Griffiths-Sattenspiel B, Wilson W (2009) the carbon footprint of water. Available via DIALOG. http:// www.rivernetwork.org/resource-library/carbon-footprint-water. Cited 15 May 2013

Han J, Zhao C, Wang $\mathrm{M}$ et al (2010) $\mathrm{CO}_{2}$ emission status and emission reduction analysis of China's cement industry. Nat Sci J Hainan Univ 28(3):252-256 (in Chinese)

Han Y, Li L, Sun N (2011) Research on carbon dioxide emission of chinese iron \& steel industry. J Nanjing Univ Inf Sci Technol 03(1):53-57 (in Chinese)

He C, Wu J, Liu W (2009) Calculation method of cement ecological footprint. Acta Ecol Sin 29(7):3549-3558 (in Chinese)

Hu A, Yan Y, Wei X (2011) China in 2030: common prosperity and Datong world. China Renmin University Press, Beijing (in Chinese)

IPCC (2007) Climate change 2007: impacts. Adaptation and vulnerability. Fourth assessment report of IPCC Working GroupII, Cambridge 
IWMI (International Water Management Institute) (2007) Water for food, water for life: a comprehensive assessment of water management in agriculture. Earthscan, and Colombo: International Water Management Institute, London

Ji Y, Lu J, Zhang $\mathrm{H}(2010) \mathrm{CO}_{2}$ emissions and main capture measures in iron and steel industry. J Nanjing Univ Inf Sci Technol 02(6):562-566 (in Chinese)

Karimi P, Qureshi AS, Bahramloo R et al (2012) Reducing carbon emissions through improved irrigation and groundwater management: a case study from Iran. Agric Water Manag 108:52-60

Kendy E, Zhang Y, Liu C et al (2004) Groundwater recharge from irrigated cropland in the North China Plain: a case study of Luancheng County, Hebei Province, 1949-2000. Hydrol Process 18:22892302

Kitamura Y, Yano T, Honna T et al (2006) Causes of farmland salinization and remedial measures in the aral sea basin-research on water management to prevent secondary salinization in rice-based cropping system in arid land. Agric Water Manag 85:1-14

Li G, Fu G (1998) Current water-saving irrigation patterns and economic benefits. Heilongjiang Science and Technology of Water Conservancy 1:15-17 (in Chinese)

Li Y, Ma K (2002) Low pressure pipe conveyance and irrigation technology - a new water-saving irrigation technology. Appl Eng Technol Rural Areas 6:13-14 (in Chinese)

Li Y, Xu Z, Lv N et al (2003) Experimental study on irrigation system for fall wheat irrigated by spray and boundary irrigation. J Irrig Drain 22:57-59 (in Chinese)

Li X, Sun X, Li J (2010) The primary research on carbon footprint for cement enterprises. China Build Mater Sci Technol (6):18-19 (in Chinese)

Lin Z (1984) The energy-saving critical equation and its application of spray irrigation. Water Saving Irrig 4:11-17 (in Chinese)

Lu X, Bai H, Zhao L et al (2010) Analysis of $\mathrm{CO}_{2}$ emissions of iron and steel making process. Energy for Metall Ind 31(1):5-9, 94 (in Chinese)

Maraseni TN, Mushtaq S, Hafeez M et al (2010) Greenhouse gas implications of water reuse in the Upper Pumpanga River integrated irrigation system, Philippines. Agric Water Manag 97(3):382-388

MIT (Massachusetts Institute of Technology) (2011) Mission 2014: feeding the world, Sustainable Agriculture. Available via DIALOG. http://12.000.scripts.mit.edu/mission2014/solutions/modernized-irrigation. Cited 15 May 2013

Moiwo J, Yang Y, Li H et al (2009) Comparison of GRACE with in situ hydrological measurement data shows storage depletion in Hai River Basin, Northern China. Water SA 35(5):663-670

MWR (Ministry of Water Resources, PRC) (2005) Technique specification for seepage prevention engineer on canal. China Water \& Power Press, Beijing (in Chinese)

MWR (Ministry of Water Resources, PRC) (2011) China water statistical yearbook 2011. China Water \& Power Press, Beijing (in Chinese)

MWR (The Ministry of Water Resources of China) (2000) SL 254-2000 code of practice for technical renovation of pumping station. Available via DIALOG. http://baike.baidu.com/view/7982909.htm. Cited 15 May 2013

NBSC (National Bureau of Statistics of China) (2011) China Statistical Yearbook 2011. NBSC, Beijing (in Chinese)

NDRC (National Development and Reform Commission of China) (2012) Second national communication on climate change of the People's Republic of China. Available via DIALOG. http://nc.ccchina.gov.cn/english/. Cited 15 May 2013

Nelson GC, Robertson R, Msangi S et al (2009) Greenhouse gas mitigation. Issues for Indian agriculture. In: IFPRI discussion paper 00900. International Food Policy Research Institute, Environment and Production Technology Division, Washington

Peng M, Wu Q, Tian M (2003) The effect of groundwater table lowering on ecological environment in the headwaters of the Yellow River. J Glaciol Geocryol 25(6):667-671 (in Chinese)

Pimentel D, Pimentel M (2003) World population, food, natural resources, and survival. World Futur 59(3-4):145-167

Rajak D, Manjunatha MV, Rajkumar GR et al (2006) Comparative effects of drip and furrow irrigation on the yield and water productivity of cotton (Gossypium hirsutum L.) in a saline and waterlogged vertisol. Agric Water Manag 83:30-36

Ran R, Weng D (2006) Current situation of $\mathrm{CO}_{2}$ emission in iron and steel producing and its controlling methods. Sci Technol Rev 24(10):53-56 (in Chinese)

Roach SS (2011) China's 12th five-year plan: strategy vs. tactics. Available via DIALOG. http://www.law.yale.edu/ documents/pdf/cbl/China_12th_Five_Year_Plan.pdf. Cited 15 May 2013

Romero P, Garcı'a J, Botı'a P (2006) Cost-benefit analysis of a regulated deficit-irrigated almond orchard under subsurface drip irrigation conditions in Southeastern Spain. Irrig Sci 24:175-184

Rothausen SGSA, Conway D (2011) Greenhouse gas emissions from energy use in the water sector. Nat Clim Chang 1:210-219 
Sloggett G (1982) Energy and US agriculture: irrigation pumping, 1974-80. Agricultural economic report United States department of agriculture

Stockle CO (2002) Environmental impact of irrigation: a review. Washington State University. Available via DIALOG. http://swwrc.wsu.edu/newsletter/fall2001/IrrImpact2.pdf. Cited 15 May 2013

Tamanyu S, Muraoka H, Ishii T (2009) Geological interpretation of groundwater level lowering in the North China Plain. Bull Geol Surv Jpn 60(1/2):105-115

Tian F, Hu H (2006) A general review of the capacity development for agricultural water management in China. Available via DIALOG. ftp://ftp.fao.org/docrep/fao/008/a0415e/a0415e07.pdf. Cited 15 May 2013

UNFCCC (United States Framework Convention on Climate Change) (2008) Challenges and Opportunities for Mitigation in the Agriculture Sector. Available via DIALOG. http://unfecc.int/resource/docs/2008/tp/ 08.Pdf.2008.17. Cited 15 May 2013

USGS (U.S. Geological Survey Circular) (2013) Estimated use of water in the United States in 2005. Available via DIALOG. http://ga.water.usgs.gov/edu/wuir.html. Cited 15 May 2013

Wang L (2006) Emission reduction of China's cement industry. China Cement 4:85-88 (in Chinese)

Wang H (2010) Analysis on the benefit of water-saving technology of agricultural irrigation engineering in Hebei Province. South-to-North Water Trans Water Sci Technol 8:99-103 (in Chinese)

Wang Y, Gao Q (2001) Economic analysis of walking sprinkler in pipe type. Heilongjiang Sci Technol Water Conservancy 02:85-86 (in Chinese)

Wang Y, Wu Y (2006) Economic analysis of several major water-saving irrigation technologies. J Econ Water Resour 6:35-40 (in Chinese)

Wang J, Rothausen SGSA, Conway D et al (2012) China's water-energy nexus: greenhouse-gas emissions from groundwater use for agriculture. Environ Res Lett 7(1):14-35

WGCNAPCC (Working Group on China's National Assessment Report on Climate Change) (2011) China's second national assessment report on climate change. China Science Press, Beijing (in Chinese)

WHYMAP (World-wide Hydrogeological Mapping and Assessment Programme) (2008) BGR Database http:// www.whymap.org/whymap/EN/Downloads/Global_maps/globalmaps_node_en.htm. Cited 15 May 2013

Wu K, Lu B, Yuan Z (2006) The recent developments and the contribution of farmland irrigation to national grain safeness in China. J Irrig Drain 25(4):7-10 (in Chinese)

Yao S, Kang Y, Liu H et al (2005) Analysis on the growth of winter wheat under sprinkler and surface irrigation conditions. Agric Res Arid Areas 23:143-147 (in Chinese)

Yohannes S, Tadesse T (1998) Effect of drip and furrow irrigation and plant spacing on yield of tomato at Dire Dawa, Ethiop. Agric Water Manag 35:201-207

Zhang M, Li Z (2007) Main points of low pressure pipe irrigation work design for gravity flow irrigation area. Guangxi Water Resour Hydropower Eng 5:42-45 (in Chinese)

Zhang C, Shangguan F, $\mathrm{Hu} \mathrm{C}$ et al (2010) Steel process structure and its impact on $\mathrm{CO}_{2}$ emission. Iron Steel 45(5):1-6 (in Chinese)

Zhou W (2010) Investigation report of China's water resources and water price. China Price 3:19-23 (in Chinese)

Zou X, Li Y, Gao Q et al (2012) How water saving irrigation contributes to climate change resilience- a case study of practices in China. Mitig Adapt Strateg Glob Chang 17:111-132 